\title{
Astrocyte Calcium Signaling Transforms Cholinergic Modulation to Cortical Plasticity In Vivo
}

\author{
Norio Takata, ${ }^{1 \star}$ Tsuneko Mishima, ${ }^{1 \star}$ Chihiro Hisatsune, ${ }^{2}$ Terumi Nagai, ${ }^{1}$ Etsuko Ebisui, ${ }^{2}$ Katsuhiko Mikoshiba, ${ }^{2,3}$ \\ and Hajime Hirase ${ }^{1,4}$ \\ ${ }^{1}$ Laboratory for Neuron Glia Circuit and ${ }^{2}$ Laboratory for Developmental Neurobiology, RIKEN Brain Science Institute, Wako, Saitama 351-0198, Japan, and \\ ${ }^{3}$ ICORP-SORST JST and ${ }^{4}$ Brain Science Institute, Saitama University, Sakura, Saitama 338-8570, Japan
}

Global brain state dynamics regulate plasticity in local cortical circuits, but the underlying cellular and molecular mechanisms are unclear. Here, we demonstrate that astrocyte $\mathrm{Ca}^{2+}$ signaling provides a critical bridge between cholinergic activation, associated with attention and vigilance states, and somatosensory plasticity in mouse barrel cortex in vivo. We investigated first whether a combined stimulation of mouse whiskers and the nucleus basalis of Meynert (NBM), the principal source of cholinergic innervation to the cortex, leads to enhanced whisker-evoked local field potential. This plasticity is dependent on muscarinic acetylcholine receptors (mAChR) and $N$-methyl-D-aspartic acid receptors (NMDARs). During the induction of this synaptic plasticity, we find that astrocytic [Ca $\left.{ }^{2+}\right]_{\mathrm{i}}$ is pronouncedly elevated, which is blocked by mAChR antagonists. The elevation of astrocytic $\left[\mathrm{Ca}^{2+}\right]_{\mathrm{i}}$ is crucial in this type of synaptic plasticity, as the plasticity could not be induced in inositol-1,4,5-trisphosphate receptor type 2 knock-out (IP ${ }_{3} \mathrm{R} 2-\mathrm{KO}$ ) mice, in which astrocytic $\left[\mathrm{Ca}^{2+}\right]_{\mathrm{i}}$ surges are diminished. Moreover, NBM stimulation led to a significant increase in the extracellular concentration of the NMDAR coagonist D-serine in wild-type mice when compared to $\mathrm{IP}_{3} \mathrm{R} 2-\mathrm{KO}$ mice. Finally, plasticity in $\mathrm{IP}_{3} \mathrm{R} 2-\mathrm{KO}$ mice could be rescued by externally supplying D-serine. Our data present coherent lines of in vivo evidence for astrocytic involvement in cortical plasticity. These findings suggest an unexpected role of astrocytes as a gate for cholinergic plasticity in the cortex.

\section{Introduction}

The brain exhibits distinct network dynamics in different states of anesthesia, wakefulness, and sleep. During slow-wave sleep, cerebral cortical local field potential (LFP) patterns are characterized by the large-amplitude slow oscillations, whereas small-amplitude and rapid fluctuations appear during states of vigilance (Steriade, 1997). Acetylcholine (ACh) is a subcortical neurotransmitter widely accepted to be involved in wakefulness and attention in the CNS (Everitt and Robbins, 1997; Sarter et al., 2005). Electrical stimulation of the nucleus basalis of Meynert (NBM), the principal source of cholinergic innervation to the cortex, transforms the synchronized LFP patterns into awake-like, desynchronized patterns in anesthetized animals, effects that are blocked by muscarinic ACh receptors (mAChRs) (Metherate et al., 1992). In addition to regulating brain

Received 0ct. 20, 2011; accepted 0ct. 29, 2011.

Author contributions: N.T., K.M., and H.H. designed research; N.T., T.M., C.H., and T.N. performed research; C.H., E.E., and K.M. contributed unpublished reagents/analytic tools; N.T., T.M., and H.H. analyzed data; N.T., T.M., and H.H. wrote the paper.

This work was supported by RIKEN intramural funds and in part by KAKENHI Grants from the Ministry of Education, Culture, Sports, Science, and Technology of Japan (19700306, 21700374, and 23700399 to N.T., 20220007 to K.M., and 18053026 and 23115522 to H.H.). We thank Dr. Toshihiko Hosoya (RIKEN), Dr. Takashi Kitamura (University of Toyama), and Dr. Kentaroh Takagaki (Georgetown University) for advice. We appreciate Dr. Hiromasa Morishita (RIKEN RRC), Dr. Nobuko Mataga (RIKEN RRC), Yurika Miyoshi (Kyushu University), and Dr. Kenji Hamase (Kyushu University) for HPLC analysis. We thank Kazuko Yahagi, Aki Hosoya, and RIKEN BSI-Olympus Collaboration Center for technical support.

*N.T. and T.M. contributed equally to this work.

The authors declare no competing financial interests.

Correspondence should be addressed to Hajime Hirase, RIKEN Brain Science Institute, 2-1 Hirosawa, Wako-shi, Saitama, 351-0198, Japan. E-mail: hirase@brain.riken.jp.

DOI:10.1523/JNEUROSCI.5289-11.2011

Copyright $\odot 2011$ the authors $\quad 0270-6474 / 11 / 3118155-11 \$ 15.00 / 0$ state changes, ACh also plays a pivotal role in plasticity of receptive fields in the cerebral cortex (Bear and Singer, 1986; Bakin and Weinberger, 1996; Kilgard and Merzenich, 1998). For instance, combined stimulation of whiskers and the NBM induces long-term synaptic plasticity in the somatosensory cortex of cats and rats (Metherate et al., 1987; Oldford and Castro-Alamancos, 2003).

Recently, it has become increasingly evident that astrocytes, a major glial cell type in the CNS, play a role in synaptic plasticity (Yang et al., 2003; Stellwagen and Malenka, 2006; Perea and Araque, 2007; Sasaki et al., 2011). Elevation of intracellular calcium concentration $\left(\left[\mathrm{Ca}^{2+}\right]_{\mathrm{i}}\right)$ in astrocytes has been reported to influence the induction of long-term potentiation within the astrocytes' domain (Henneberger et al., 2010) in hippocampal slice experiments, although the finding remains controversial (Agulhon et al., 2010). Here, we demonstrate first that a combined stimulation of mouse whiskers and NBM leads to enhanced whisker-evoked LFP in the barrel cortex. During the induction of this synaptic plasticity, we find that astrocytic $\left[\mathrm{Ca}^{2+}\right]_{\mathrm{i}}$ is elevated in a mAChR-dependent manner. The elevation of astrocytic $\left[\mathrm{Ca}^{2+}\right]_{\mathrm{i}}$ is crucial in this type of synaptic plasticity, as the plasticity could not be induced in inositol-1,4,5-trisphosphate receptor type 2 knock-out $\left(\mathrm{IP}_{3} \mathrm{R} 2-\mathrm{KO}\right)$ mice, in which astrocytic $\left[\mathrm{Ca}^{2+}\right]_{\mathrm{i}}$ is diminished. Moreover, NBM stimulation led to a significant increase in extracellular concentration of the NMDA receptor (NMDAR) coagonist D-serine (D-Ser) in wild-type (WT) mice when compared to $\mathrm{IP}_{3} \mathrm{R} 2-\mathrm{KO}$ mice. These results suggest that NBM activity sets a favorable condition for the induction of synaptic plasticity by triggering astrocytic $\left[\mathrm{Ca}^{2+}\right]_{\mathrm{i}}$ activity in vivo. 
A

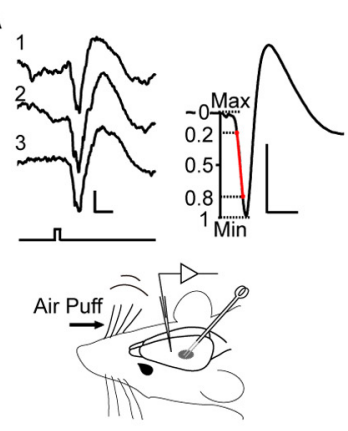

D



B

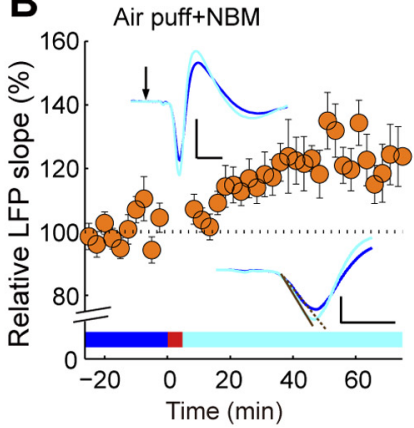

E

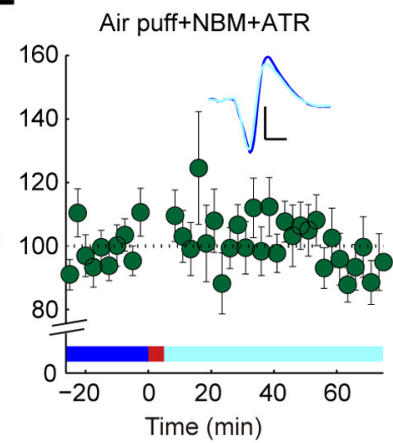

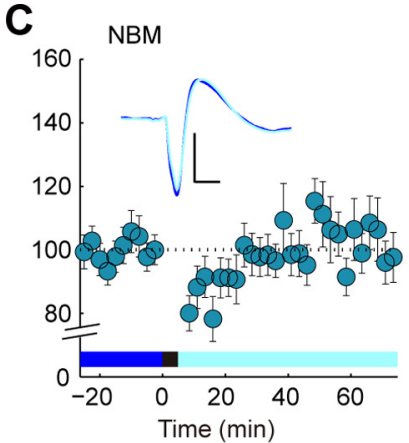

$\mathbf{F}$

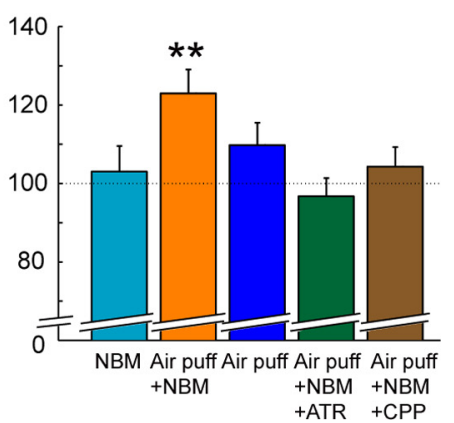

Figure 1. Paired stimulation of whiskers and NBM induces enhancement in LFP response in the barrel cortex. $A$, Experimental setup and representative LFP responses to whisker stimulation. Top left, Air puff on whiskers was applied every $10 \mathrm{~s}$, which triggered a reliable LFP response in the barrel cortex. The traces are three consecutive LFP responses aligned to the air puff application time (bottom trace). The bottom line with a tick indicates when whisker stimulation was applied. Top right, LFP slope is calculated as the slope of the $20-80 \%$ amplitude interval of the initial negative deflection (indicated in red). Bottom right, The bipolar stimulation electrode was positioned at the NBM. Scale bar: $200 \mu \mathrm{V}, 20 \mathrm{~ms}$ for top right and left panels. Max, Maximum; Min, minimum. $\boldsymbol{B}$ - $\boldsymbol{E}$, Time course of whisker stimulation-evoked LFP slopes. Costimulation of whiskers and NBM ( 5 min, red bar) induced an enhancement in LFP responses ( $\boldsymbol{B})$. NBM ( $\boldsymbol{C}$, black bar) or air puff ( $\boldsymbol{D}$, cyan bar) stimulation alone did not increase LFP responses. LFP enhancement by costimulation was blocked by atropine $(\boldsymbol{E})$ or $(P P(\boldsymbol{F})$, suggesting that the plasticity is mAChR and NMDAR dependent. Insets are representative averaged evoked responses in control period (blue) and $60 \mathrm{~min}$ after costimulation (light blue). Scale bars: $200 \mu \mathrm{V}, 20 \mathrm{~ms}$. Inset at the bottom right in $\boldsymbol{B}$ is an expanded view of the representative LFPs with fitted slopes (dotted line, control period; solid line, after costimulation). Scale bars: $200 \mu V, 10$ ms. $\boldsymbol{F}$, Summary bar graphs for LFP enhancement 60 min after each stimulation in various experimental conditions $\left({ }^{* *} p<0.01\right)$.

\section{Materials and Methods}

Subjects and surgery. Male C57BL/6 mice or $\mathrm{IP}_{3} \mathrm{R} 2-\mathrm{KO}$ mice (Futatsugi et al., 2005), postnatal 8-12 weeks old, were deeply anesthetized with $1.6 \sim 1.65 \mathrm{~g} / \mathrm{kg}$ as described previously (Sakatani et al., 2007). Urethane was supplemented with $1 / 15$ of the initial dose as necessary. Physiological saline $(0.9 \% \mathrm{NaCl})$ containing dextrose $(5 \%, \mathrm{w} / \mathrm{v})$ was also injected subcutaneously (up to $10 \mathrm{ml} / \mathrm{kg} / \mathrm{h}$ ) to maintain the fluid balance. The body temperature was maintained at $37^{\circ} \mathrm{C}$ with a heating pad (TR-200, Fine Science Tools) during surgery and imaging. After skull exposure, a metal frame was attached to the skull using a dental acrylic (Fuji LUTE BC, GC Corporation). A craniotomy ( $2 \mathrm{~mm}$ in diameter), centered $1.0 \mathrm{~mm}$ posterior to the bregma (AP $-1.0 \mathrm{~mm}$ ) and $3.4 \mathrm{~mm}$ lateral from the midline (ML $3.4 \mathrm{~mm}$ ), was made over the somatosensory barrel cortex for twophoton imaging, multichannel extracellular recording, or microdialysis experiments. The dura mater was surgically removed. Another craniotomy, located ipsilaterally at AP $\sim-4 \mathrm{~mm}$ and $\mathrm{ML} \sim 1.5 \mathrm{~mm}(1.5 \mathrm{~mm}$ diameter), was prepared for insertion of a NBM stimulation electrode. Two screw electrodes (diameter, $0.7 \mathrm{~mm}$; SUS-XM7, no. 00PH+14046, Matsumoto Industry) were implanted in the interparietal bone to serve as reference and ground for LFP recording. Electrocardiogram was measured by placing an electrode near the chest and taking a reference signal from the ipsilateral hind leg of the subject. All experimental protocols were approved by the RIKEN Institutional Animal Care and Use Committee.

Stimulation of whiskers. Whiskers were trimmed to $10 \mathrm{~mm}$ in length and stimulated by a brief air puff ( $\sim 70 \mathrm{kPa}, 5 \mathrm{~ms}$ duration) using a pneumatic pressure pump (PV820 or 830 , WPI). A programmable generator (WF1973, NF Corporation or Master-8-vp, A.M.P.I.) was used to control stimulation timing. Air puffs were delivered through a tube (diameter $2.45 \mathrm{~mm}) \sim 15 \mathrm{~mm}$ rostral to the C6 whisker and positioned contralateral to the recording hemisphere. Three paradigms of air puff were used: (1) "low-frequency air puff" (LFAP) is air puffs applied every $10 \mathrm{~s}$ for a given period and used to measure the local field potential response to whisker stimulation; (2) "high-frequency air puff" consists of air puffs delivered $5 \mathrm{~Hz}$ for $30 \mathrm{~s}$; and (3) "paired air puff/NBM costimulation" (costimulation) is a combined presentation of electrical stimulation of NBM (for details see next paragraph) and air puffs delivered every $3 \mathrm{~s}$ for $5 \mathrm{~min}$.

Stimulation of the nucleus basalis of Meynert. For electrical stimulation of the nucleus basalis of Meynert, a bipolar tungsten electrode (tip distance, $\sim 300 \mu \mathrm{m}$ ) was inserted from the posterior craniotomy with an angle of $40 \sim 50^{\circ}$ to reach at NBM $(\sim 5800 \mu \mathrm{m}$ in penetration depth). Successful stimulation of NBM was confirmed by the following: (1) cortical LFP transition from the slow wave to the desynchronized state; and (2) post hoc histological localization of the stimulating electrode tip, combined with immunohistochemical detection of choline acetyltransferase (ChAT) (see below, Histology). A single-train NBM stimulation (stNBM) is comprised of 500 pulses $(200 \mu \mathrm{A}, 0.1 \mathrm{~ms}, 100 \mathrm{~Hz})$. During costimulation, NBM stimulation preceded each air puff stimulation by $100 \mathrm{~ms}$.

Multichannel extracellular recording. Simultaneous 16-channel extracellular recordings were made using a linear silicon probe (16 sites, 50 $\mu \mathrm{m}$ spacing, $177 \mu \mathrm{m}^{2}$ recording site area; NeuroNexus Technologies) coated with the lipophilic fluorescent dye DiI (D-282, Invitrogen). The silicon probe was vertically inserted into the barrel cortex. The silicon probe was gently progressed until all of the sites were in the cortex. Electrophysiological signals were recorded as described previously using L8 amplifiers (Neuralynx) and a LabVIEW-based data acquisition system (National Instruments). Recording sessions started $2 \sim 2.5 \mathrm{~h}$ after insertion of the silicon probe for stabilization of evoked LFP (Gilbert and 
A
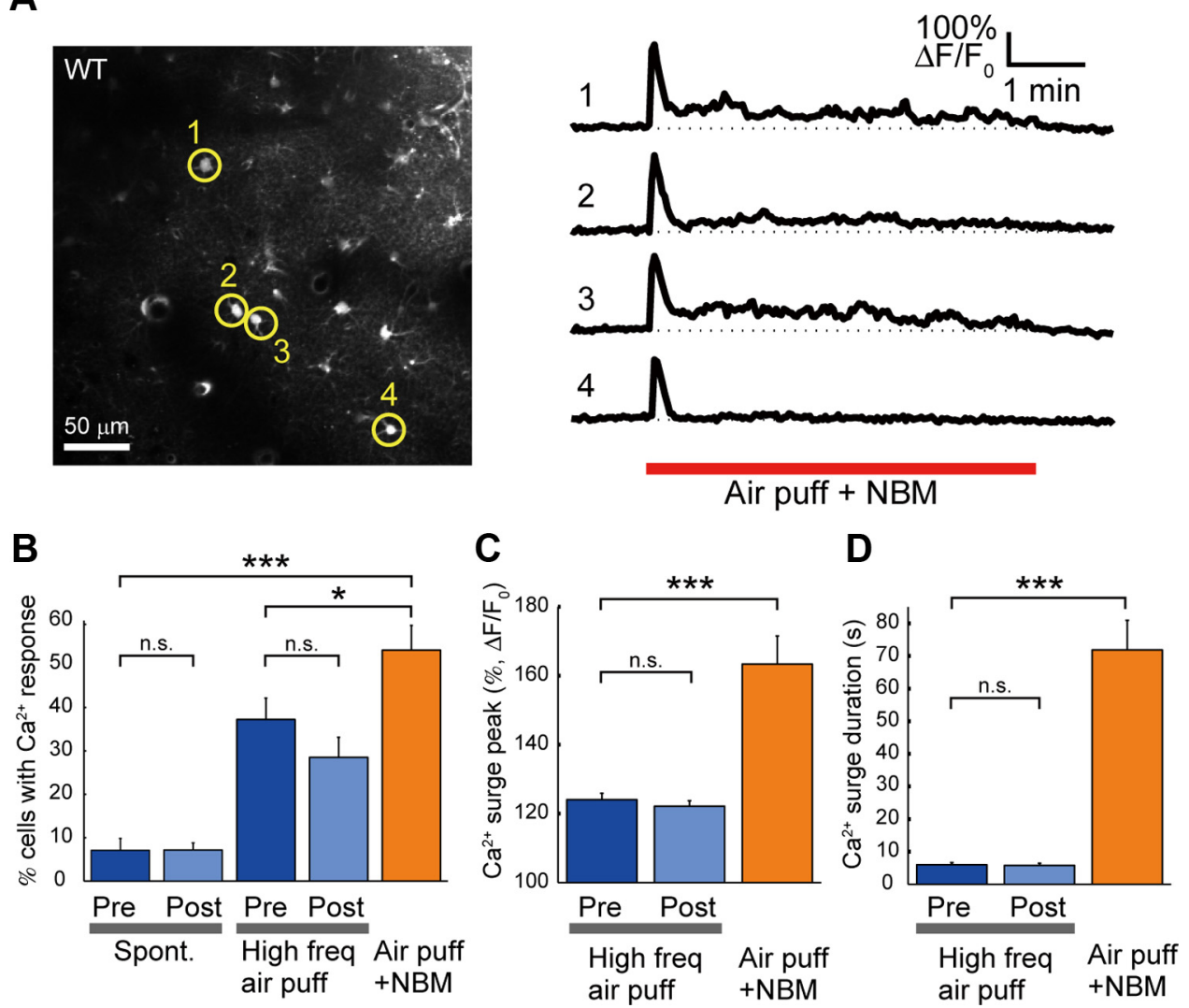

Figure 2. Astrocytes responded with $\left[\mathrm{Ca}^{2+}\right]_{\mathrm{i}}$ surge upon costimulation of whiskers and NBM. $A$, Representative in vivo image of the barrel cortex loaded with the $\mathrm{Ca}^{2+}$ fluorescent dye Fluo-4 $\mathrm{AM}$, which predominantly labels astrocytes. Costimulation (Air puff $+\mathrm{NBM}$, red bar) induced a large transient $\left[\mathrm{Ca}^{2+}\right]_{\mathrm{i}}$ elevation, typically followed by continual $\left[\mathrm{Ca}^{2+}\right]_{\mathrm{i}}$ surges for the rest of the stimulation period (e.g., cells 1-3). Numbers correspond to the astrocytes in the left panel. B, Bar graph comparing the proportion of astrocytes with at least one $\left[\mathrm{Ca}^{2+}\right]_{i}$ surge (active astrocytes). 'Pre' and 'Post' denote the period before and after costimulation (Air puff + NBM), respectively. The costimulation significantly increased the percentage of active astrocytes. The percentage of active astrocytes did not change significantly between Pre and Post in either spontaneous or high-frequency air puff conditions. Spont., Spontaneous activity; High freq air-puff, repetitive air-puff stimulation (5 Hz, $30 \mathrm{~s})$. $\boldsymbol{C}, \mathbf{D}$, Astrocytic $\left[\mathrm{Ca}^{2+}\right]_{\mathrm{i}}$ surge peak ( $\boldsymbol{C}$ and duration $(\boldsymbol{D})$ during costimulation were larger when compared with High freq air puff-induced $\left[\mathrm{Ca}^{2+}\right]_{\mathrm{i}}$ surges. ${ }^{*} p<0.05$, ${ }^{* * *} p<0.001$.

Mack, 1999). During this recovery period, air puff stimulation was applied every $20 \mathrm{~s}$ to monitor the stability of evoked potentials. A recording session started with 30 min of LFAP followed by costimulation and concluding with 90 min of LFAP. In some control experiments, the costimulation period was replaced by either whisker stimulation only or NBM stimulation only.

Dye loading and in vivo two-photon imaging. Two-photon imaging was performed with multicell bolus loading or surface application of fluorescent indicator, as described previously (Hirase et al., 2004; Takata and Hirase, 2008). For multicell bolus loading, the $\mathrm{Ca}^{2+}$-sensitive fluorescent indicator Oregon Green 488 BAPTA-1 (OGB-1) and an astrocytespecific marker, SR101, were used. Briefly, the dye-containing solution was prepared with the following reagents: OGB-1 AM (50 mg, O-6807, Invitrogen), Pluronic F-127 (10 $\mu \mathrm{l}$, P3000MP, Invitrogen), HEPESartificial cerebrospinal fluid (ACSF, $34 \mu \mathrm{l}, \mathrm{pH}$ 7.4), and SR101 (6 $\mu \mathrm{l}$ of $0.24 \mathrm{~mm}$ solution, S-359, Invitrogen). A quartz glass micropipette of tip diameter $\sim 10 \mu \mathrm{m}$ containing $5 \mu \mathrm{l}$ of the dye mixture was slowly inserted into the cortex (200 $\mu \mathrm{m}$ below the pia), and dye application was made by air pressure $(70 \mathrm{kPa}, 1 \mathrm{~min})$. For surface application, Fluo-4 AM was applied on the exposed cortex to stain astrocytes in the superficial layer. Briefly, Fluo-4 AM (1 mM) was dissolved in Pluronic F-127 and mixed in ACSF. ACSF containing Fluo-4 AM $(10 \mu \mathrm{l})$ was dropped on the pial surface of the craniotomy. After a 60 min incubation, the exposed brain was washed for $15 \mathrm{~min}$ with dye-free ACSF. After the dye loading, the craniotomy was covered with agarose $(1.5 \% \mathrm{w} / \mathrm{v}$ in ACSF) and sealed by placing a thin glass coverslip $(3 \mathrm{~mm} \times 3 \mathrm{~mm}$, thickness, $0.12 \mathrm{~mm}$, Matsunami Glass, leaving the lateral side of the craniotomy open for insertion of a glass electrode for LFP measurement. The cranial window was secured by dental cement. Imaging was performed with a custom- modified Olympus FV-1000-based two-photon microscope. Chameleon XR laser (Coherent) was used as the excitation light source. The group velocity dispersion was compensated by a prism-coupled prechirper, and the beam diameter was adjusted by a Kepler telescope. The output power of the laser power was adjusted by a motorized polarizing prism. Laser power $(\mathrm{mW})$ measured after the objective lens (LUMPLANFL40XW, N.A. 0.8 , Olympus) was $<10 \mathrm{~mW}$ with A laser irradiation time of 12.5 $\mu$ s/pixel. Fluorescent dye-loaded areas $(320 \mu \mathrm{m} \times 320 \mu \mathrm{m})$ were imaged 3 min for "Spontaneous" or "High freq air puff" measurement and $7 \mathrm{~min}$ for "Air puff + NBM" measurement, at $0.5 \mathrm{~Hz}$ with $320 \times 320$ pixels from 29 urethane-anesthetized mice. Before and after the costimulation, $3 \sim 5$ measurements were performed for Spontaneous and High freq air puff, respectively.

Drug application. For pharmacological experiments, the following drugs in HEPES-ACSF (in mM: $125 \mathrm{NaCl}, 5 \mathrm{KCl}, 10$ glucose, 10 HEPES, 2 $\mathrm{CaCl}_{2}, 2 \mathrm{MgSO}_{4}$ ) were applied on the cranial window: atropine sulfate monohydrate (ATR, 2 4 mM, catalog no. 015-04853, Wako Pure Chemical Industries); 3-(2-carboxypiperazin-4-yl) propyl-1-phosphonic acid (CPP, $20 \mu \mathrm{M}, \mathrm{C104}$, Sigma-Aldrich); D-Ser (100 $\mu \mathrm{M}$, catalog no. 19708823, Wako Pure Chemical Industries). In some experiments, intraperitoneal injection of ATR (5 mg/kg), CPP (10 mg/kg), D-Ser (560 mg/ $\mathrm{kg}$ ), or 2-methyl-6-(phenylethynyl)-pyridine (MPEP, $10 \mathrm{mg} / \mathrm{kg}$, catalog no. 131-15471, Wako Pure Chemical Industries) was performed before costimulation. These systemic injections were performed $30 \mathrm{~min}$ (ATR, MPEP), $120 \mathrm{~min}$ (CPP), or $0 \mathrm{~min}$ (D-Ser) before the conjunctive stimulation, respectively.

In vivo microdialysis. A straight-shaped cellulose dialysis probe (1.0 $\mathrm{mm}$ in length, $350 \mu \mathrm{m}$ outer diameter, 50,000 Da cutoff, A-I-4-01, EICOM) was slowly inserted to the barrel cortex of anesthetized mice. 
A
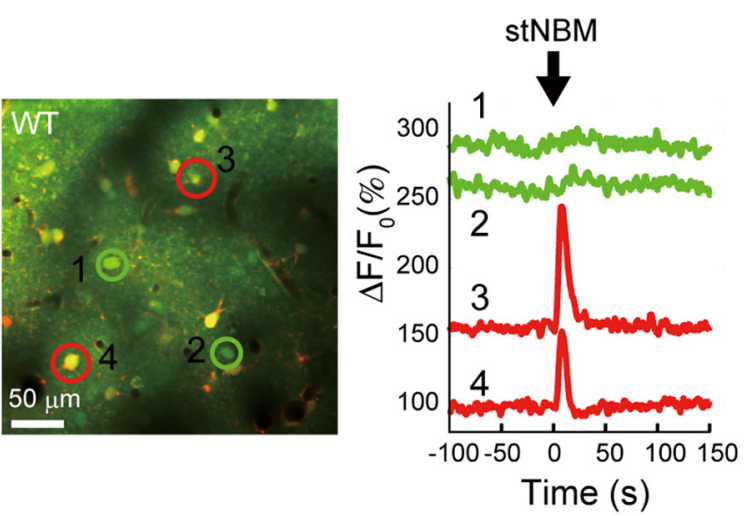

C

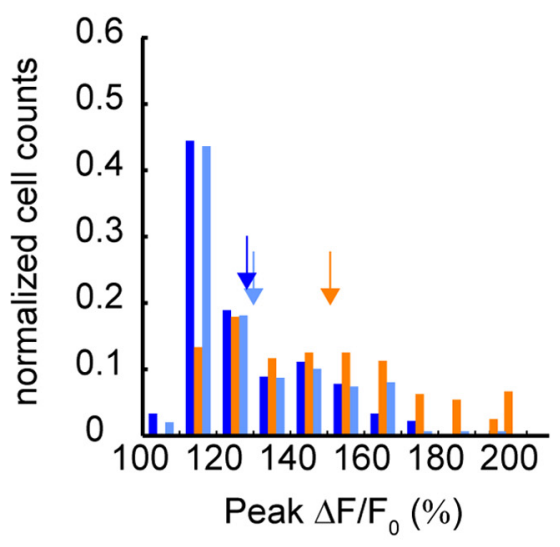

Astrocytes

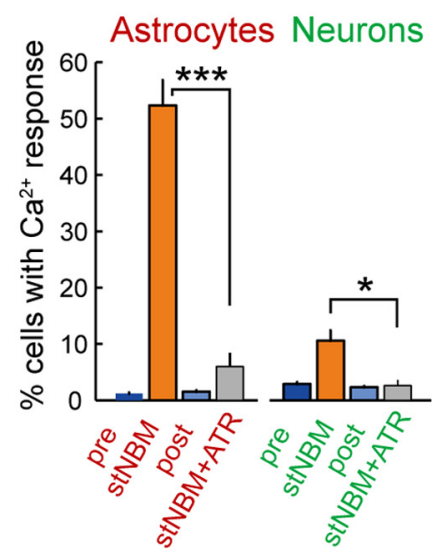

B

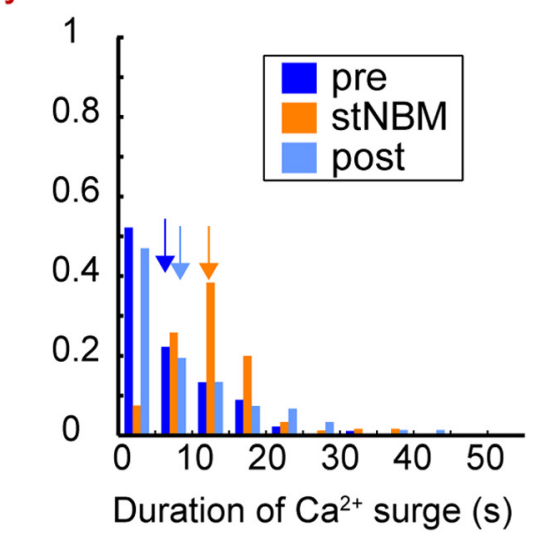

D

\section{Neurons}
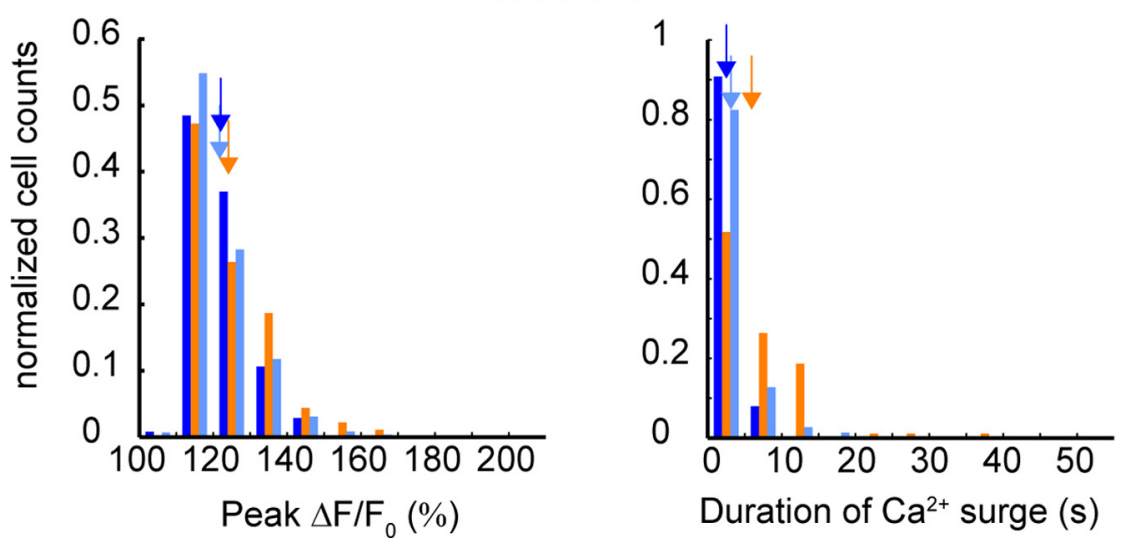

Figure 3. Properties of astrocytic and neuronal $\left[\mathrm{Ca}^{2+}\right]_{\mathrm{i}}$ events upon stNBM. $A$, Left, Representative in vivo image of the barrel cortex loaded with the $\mathrm{Ca}^{2+}$ fluorescent dye $0 \mathrm{~GB}-1 \mathrm{AM}$ and an astrocyte marker, SR101. Right, OGB-1 fluorescent signals from astrocytes (cell 3s and 4) show large responses upon stNBM, whereas neuronal responses (cells 1 and 2) are modest. B, Bar graph comparing percentage of responsive astrocytes and neurons to stNBM in the absence or presence of atropine, ATR. ${ }^{*} p<0.05,{ }^{* * *} p<0.001$. $C, D$, Histograms of $\left[C a^{2+}\right]_{i}$ surge peak and duration are computed for astrocytes $(\boldsymbol{C})$ and neurons $(\boldsymbol{D})$ before, immediately following, or after stNBM, denoted as pre, stNBM, and post, respectively. Arrows indicate the means of $\left[C^{2+}{ }^{2+}\right]_{i}$ surge peak and duration for each distribution. Astrocytic $\left[\mathrm{Ca}^{2+}\right]_{\mathrm{i}}$ events evoked by stNBM had significantly higher $\left[\mathrm{Ca}^{2+}\right]_{\mathrm{i}}$ surge peak $(p<0.001)$ and longer duration $(p<0.001)$ compared with those of control periods, whereas the differences were less obvious for neurons. The distributions were similar between the two control periods (i.e., pre vs post).

The probe was equilibrated for at least $120 \mathrm{~min}$ following insertion while perfusing with $2 \mu \mathrm{l} / \mathrm{min}$ HEPES-ACSF. Dialysate samples were collected every $10 \mathrm{~min}$. After probe stabilization, NBM stimulation $(1 \mathrm{~mA}, 50 \mathrm{~Hz}$, $10 \mathrm{~min}$ ) was applied. Relatively intense NBM-stimulation protocol was employed to achieve high ACh release in the cortex (Kurosawa et al., 1989) considering the time resolution of the microdialysis sample collection. The degree of LFP desynchronization by stNBM did not differ significantly before and after the microdialysis experiment (before $24 \pm$ $5 \mathrm{~s}$ vs after $36 \pm 15 \mathrm{~s}, n=5, p=0.51)$. Dialysate samples were collected for at least $30 \mathrm{~min}$ after the stimulation. In vitro recovery for dialysis probes was determined by placing the probes in HEPES-ACSF that contained known concentrations of D-Ser at a flow rate of $2 \mu \mathrm{l} / \mathrm{min}$, and consecutive $10 \mathrm{~min}$ samples were collected yielding the recovery rate of $6.3 \%$. After completion of the dialysis experiments, the location of the dialysis probe in the barrel cortex was verified with $60-\mu \mathrm{m}$-thick serial coronal sections of the perfusion-fixed brain.

High-performance liquid chromatographic analysis. The determination of D-Ser concentration in the dialysate was accomplished by high- 



Figure 4. Acetylcholine injection induced astrocytic $\left[\mathrm{Ca}^{2+}\right]_{\text {s }}$ surge in vivo. Left, Representative in vivo image of the barrel cortex layer 2/3. Astrocytes were loaded with the $\mathrm{Ca}^{2+}$ indicator Fluo-4 AM (green). A pipette (dotted lines) containing $1 \mathrm{~m} \mathrm{ACh}$ and $5 \%$ Texas Red-dextran (red) in ACSF were placed in the somatosensory cortex with a holding current of $-20 \mathrm{nA}$. Right, The time course of astrocytic $\left[\mathrm{Ca}^{2+}\right]_{\mathrm{i}}$. Numbers correspond to the astrocytes in the left panel. Electrophoresis of $\mathrm{ACh}\left(100 \mathrm{nA}\right.$ for $15 \mathrm{~s}$, red shaded area) induced $\left[\mathrm{Ca}^{2+}\right]_{i}$ surges in astrocytes.

performance liquid chromatography (HPLC) and fluorometric detection (Hashimoto et al., 1995). The dialysate sample was derivatized with Boc-L-Cys and $O$-phthalaldehyde for $2 \mathrm{~min}$ at $35^{\circ} \mathrm{C}$. The amino acid derivative was immediately applied to the HPLC system (SCL-10AVP, Shimadzu) and separated on a $5 \mu \mathrm{m}$ LiChroCART column $(250 \mathrm{~mm}$, inner diameter $4.0 \mathrm{~mm}$, Merck). The column was operated at a constant flow rate of $0.8 \mathrm{ml} / \mathrm{min}$ at $40^{\circ} \mathrm{C}$. Mobile phase A was $0.1 \mathrm{M}$ acetate buffer, pH 6.0 , and mobile phase B was $100 \%$ acetonitrile. The separation of amino acid derivatives was performed with a stepwise gradient using mobile phase A and B in $50 \mathrm{~min}$. Fluorescent amino acid derivatives were detected in an RF-10Axl spectrofluorometer (Shimadzu). Excitation and emission wavelengths were 350 and $450 \mathrm{~nm}$, respectively. The detection limit of the HPLC system for D-Ser was in the subpicomole range. In some experiments, the D-Ser level was determined by the more sensitive 2D-HPLC method (Miyoshi et al., 2009; Hamase et al., 2010) performed by Shiseido Corporation, yielding similar baseline levels and fluctuations.

Histology. After electrophysiological, imaging, or microdialysis experiments, the tip of the electrode was marked by passing $20 \mu \mathrm{A}$ for $30 \mathrm{~s}$ in both polarities. Animals were then deeply anesthetized with urethane and transcardially perfused with physiological saline, followed by $150 \mathrm{ml}$ of $0.1 \mathrm{M}$ phosphate buffer ( $\mathrm{PB}, \mathrm{pH} 7.4)$ containing $4 \%$ paraformaldehyde. Coronal sections corresponding to the location of the stimulation electrode tip were cut at $60 \mu \mathrm{m}$ thickness in $0.1 \mathrm{M} \mathrm{PB}$ using a microslicer (Pro-7 LinearSlicer, Dosaka EM). Slices were immunostained with antiChAT rabbit polyclonal antibody (1:1000 dilution, catalog no. AB143, Millipore) and developed with a standard ABC/Ni-DAB method to confirm the position of the stimulating electrode tip. For immunohistochemical detection of $\mathrm{IP}_{3} \mathrm{R} 2$, coronal slices containing a barrel cortex at $100 \mu \mathrm{m}$ thickness were prepared. Penetration $(0.2 \%$ Triton/PBS, $1 \mathrm{~h}$ at room temperature $)$ and retrieving $(0.01 \mathrm{M}$ citric acid, $10 \mathrm{~min})$ procedures were conducted. Slices were immunostained with anti-S100B mouse monoclonal antibody (1:1500 dilution, BD Biosciences) and anti-IP ${ }_{3} \mathrm{R} 2$ rabbit polyclonal antibody (1:100 dilution, catalog no. AB3000, Millipore Bioscience Research Reagents). Subsequently, slices were incubated with fluorescent secondary antibodies of Alexa Fluor 488-conjugated anti-mouse antibody (1:1000 dilution) and Alexa Fluor 594-conjugated anti-rabbit antibody (1:1000 dilution). Fluorescence images were obtained with an Olympus FV1000D confocal microscope (see Fig. 5).

Data analysis. Analysis on LFP, fluorescence signal, and D-Ser concentration was performed with custom software using MATLAB (MathWorks) running on a Linux-based computer. LFP response to whisker stimulation is an average of 15 sequentially obtained responses to air puffs. The LFP slope was calculated as described previously by Glazewski et al. (1998). First, the initial deflection of the LFP response was isolated. Next, the slope calculation region was defined as the interval within 20 to $80 \%$ of the peak-to-peak amplitude of the negative deflection (see Fig. 1A). The slope was computed by linear regression of the selected region.

Fluorescence signals of in vivo two-photon imaging were quantified by measuring the mean pixel values of semiautomatically selected somatic areas. Astrocytes with $\left[\mathrm{Ca}^{2+}\right]_{\mathrm{i}}$ response were detected when their fluorescence intensity $\left(\Delta F / F_{0}\right)$ exceeded $50 \%$ in Fluo- 4 experiments and $3 \times$ SD of OGB- 1 imaging. The baseline fluorescence intensity for each cell was defined as the mean of the lower two-thirds of the fluorescence intensity histogram imaged in the absence of any stimulation. The surge peaks of $\left[\mathrm{Ca}^{2+}\right]_{\mathrm{i}}$ in Fluo-4 imaging were detected when the fluorescence intensity exceeded $3 \times$ SD of the baseline. Duration of each $\left[\mathrm{Ca}^{2+}\right]_{\mathrm{i}}$ surge was defined as the duration of fluorescence intensity around $\mathrm{a}\left[\mathrm{Ca}^{2+}\right]_{\mathrm{i}}$ surge peak above 2 (Fluo-4) or 1 (OGB-1) $\times$ $\mathrm{SD}$ of the baseline. D- Ser concentration was calculated using the area under the curve (AUC) of chromatogram corresponding to D-Ser (Hashimoto et al., 1995). The average of AUC preceding NBM stimulation was used as control value (defined as 100\%). All data are expressed as mean \pm SEM, except where otherwise noted. Two-tailed $t$ tests were used for comparisons of two population means, unless otherwise noted.

\section{Results}

\section{Costimulation of whiskers and NBM induces cortical plasticity}

We measured LFP responses to whisker stimulations by air puff in layer $2 / 3$ of the contralateral barrel cortex in urethaneanesthetized mice (Fig. $1 A$ ). The onset of the LFP response occurred $\sim 20-30 \mathrm{~ms}$ after whisker stimulation. The slope of the initial negativity of the LFP response was stable over the control period of $25 \mathrm{~min}$, with whisker stimulation only $(0.1 \mathrm{~Hz}$, Fig. $1 B)$. When whisker stimulation $(0.33 \mathrm{~Hz}$ for $5 \mathrm{~min})$ was combined with electrical stimulation of the NBM $(200 \mu \mathrm{A}$, pulse duration $0.5 \mathrm{~ms}, 100 \mathrm{~Hz}$ for $0.5 \mathrm{~s}$ ) repeatedly, the LFP response upon whisker stimulation $(0.1 \mathrm{~Hz})$ gradually increased in $40 \mathrm{~min}$ and remained potentiated for the rest of the experiment $(123 \pm 6 \%$, $n=15$ mice, $p<0.01,60$ min after the combined stimulation, compared to the control period; Fig. $1 B$ ). NBM or whisker stimulation alone did not potentiate the evoked LFP slope significantly (NBM: $103 \pm 7 \%, n=15$ mice, $p=0.66$; Air puff: $110 \pm 5 \%, n=16$ mice, $p=0.12$, Fig. $1 C, D)$. Moreover, the long-term potentiation (LTP) of LFP slope by costimulation of whiskers and NBM was blocked in atropine-treated mice ( $97 \pm 5 \%, n=14$ mice, $p=0.51$, Fig. $1 E$ ) and CPP-treated mice ( $104 \pm 5 \%, n=11$ mice, $p=0.42$ ), indicating that the LTP is dependent on activation of $\mathrm{mAChRs}$ and NMDARs, respectively (Fig. $1 F$ ).

\section{Astrocytic $\left[\mathrm{Ca}^{2+}\right]_{\mathrm{i}}$ is elevated by NBM stimulation}

To investigate the possible role of astrocytes in induction of synaptic plasticity, we monitored astrocytic $\left[\mathrm{Ca}^{2+}\right]_{\mathrm{i}}$ dynamics in layer $2 / 3$ of the barrel cortex by two-photon microscopy during whisker/NBM costimulation (Fig. 2A). The cortex was loaded with the calcium-sensitive dye Fluo-4 AM, which is preferentially taken up by astrocytes, and imaged using previously reported methods (Hirase et al., 2004). Significantly higher proportions of astrocytes had $\left[\mathrm{Ca}^{2+}\right]_{\mathrm{i}}$ surges $\left(\Delta F / F_{0}>50 \%\right)$ during the costimulation period than during the control period (Fig. 2 B: $53 \pm$ 
$6 \%$ during costimulation vs spontaneous Pre $7 \pm 2 \%, p<0.001$ or vs High freq air puff Pre $37 \pm 5 \%, p=0.03,328$ astrocytes in 14 mice for costimulation), whereas the proportion of spontaneously active astrocytes did not change after costimulation (Fig. 2B: $7 \pm 2 \%$ before costimulation vs $7 \pm 1 \%$ after costimulation, $p=0.97$, 2264 and 2762 astrocytes in 14 mice, respectively), suggesting that astrocytic $\left[\mathrm{Ca}^{2+}\right]_{\mathrm{i}}$ activity was not modified upon LTP. In agreement with a previous report (Wang et al., 2006), low-frequency deflection of whiskers $(0.33 \mathrm{~Hz}, 5 \mathrm{~min})$ did not evoke an astrocytic $\left[\mathrm{Ca}^{2+}\right]_{\mathrm{i}}$ response (proportion of responsive astrocytes: Low freq air puff $7 \pm$ $1 \%$ vs Spontaneous Pre $7 \pm 2 \%, p=0.90$, 1068 and 1242 astrocytes in 14 mice, respectively), whereas a train of highfrequency air puffs $(5 \mathrm{~Hz}, 30 \mathrm{~s}$, High freq air puff) did. The proportion of highfrequency whisker-stimulation-evoked responsive astrocytes did not change after costimulation (Fig. $2 \mathrm{~B}$ : High freq air puff Pre $37 \pm 5 \%$ vs Post $29 \pm 5 \%, p=$ $0.06,1196$ and 1520 astrocytes in 14 mice, respectively). Significantly, both the $\Delta F / F_{0}$ peak and duration of astrocytic $\left[\mathrm{Ca}^{2+}\right]_{\mathrm{i}}$ responses were higher during costimulation than high-frequency air puff (Fig. $2 C, D, p<0.001$ ). We next observed $\left[\mathrm{Ca}^{2+}\right]_{\mathrm{i}}$ changes in both astrocytes and neurons in response to a single-train stimulation of NBM $(40 \mu \mathrm{A}, 100 \mathrm{~Hz}$ for $0.5 \mathrm{~s})$. To monitor both neuronal and astrocytic $\left[\mathrm{Ca}^{2+}\right]_{\mathrm{i}}$ changes, the cortex was loaded with the calcium-sensitive dye OGB-1AM and an astrocyte marker SR101 (Fig. 3A). Upon stNBM, $52 \pm 4 \%$ of astrocytes and $11 \pm 2 \%$ of neurons showed $\left[\mathrm{Ca}^{2+}\right]_{\mathrm{i}}$ surges within $10 \mathrm{~s}$ (Fig. 3B: stNBM, 4094 neurons and 1276 astrocytes in 12 mice). These figures are significantly higher than spontaneous activity observed either before stNBM stimulation (Fig. 3B: $1.4 \pm$ $0.3 \%$ and $3.8 \pm 0.5 \%$ in astrocytes and neurons, respectively, $p<0.001$ ) or after stNBM stimulation (Fig. $3 B: 1.8 \pm 0.3 \%$ and $3.2 \pm 0.4 \%$ in astrocytes and neurons, respectively, $p<0.001)$. Moreover, the $\Delta F / F_{0}$ peak value and duration of astrocytic $\left[\mathrm{Ca}^{2+}\right]_{\mathrm{i}}$ surges were also increased during stNBM (Fig. 3C,D). Atropine treatment significantly reduced the proportion of NBM-evoked active astrocytes (Fig. 3B: stNBM $52 \pm 4 \%$ vs stNBM + ATR $6.0 \pm 2.3 \%, p<0.001,158$ astrocytes in 3 mice for stNBM + ATR) and neurons (Fig. 3B: stNBM $11 \pm$ $2 \%$ vs stNBM + ATR $2.6 \pm 1.5 \%, p=0.02,105$ neurons in 3 mice for stNBM +ATR). Astrocytes express mAChRs (Van Der Zee et al., 1993), and their activation leads to $\left[\mathrm{Ca}^{2+}\right]_{\mathrm{i}}$ elevation from internal stores (Shelton and McCarthy, 2000; Araque et al., 2002). In fact, in vivo iontophoretic injection of ACh into the barrel cortex induced $\left[\mathrm{Ca}^{2+}\right]_{\mathrm{i}}$ responses in $54 \pm 9 \%$ astrocytes in the imaging field (Fig. 4: 254 astrocytes in 3 mice). Mean value of $\left[\mathrm{Ca}^{2+}\right]_{\mathrm{i}}$ surge peak was $233 \pm 8 \%$. To exclude the possibility that the astrocytic $\left[\mathrm{Ca}^{2+}\right]_{\mathrm{i}}$ increases are triggered by metabotropic

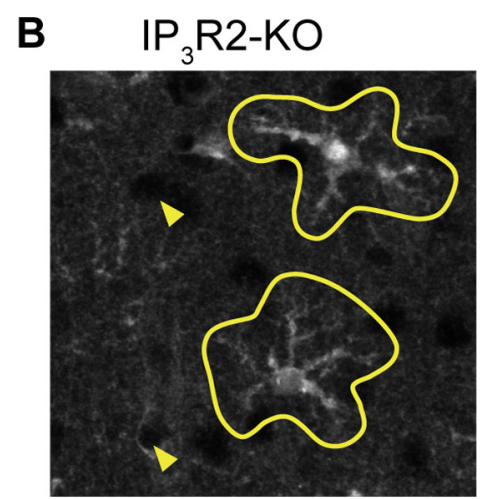

D

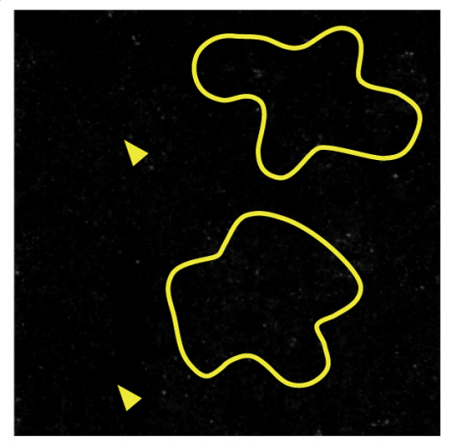

$\mathbf{F}$

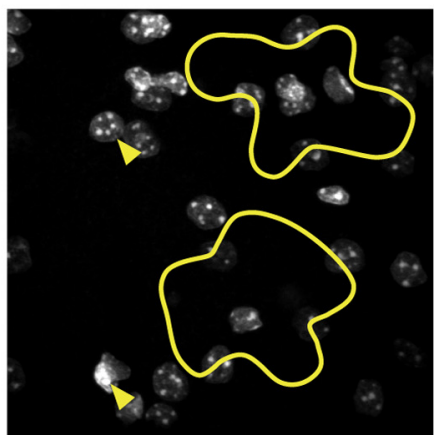

Figure 5. Double immunohistochemistry for $\mathrm{S} 100 \mathrm{~B}$ (astrocyte) and $I \mathrm{P}_{3} \mathrm{R} 2$ with $\mathrm{DAPI}$ staining in the barrel cortex. $\boldsymbol{A}, \boldsymbol{B}, \mathrm{Immu}$ nohistochemistry for the astrocytic protein $\mathrm{S} 100 \mathrm{~B}$ in WT and IP ${ }_{3} \mathrm{R} 2-\mathrm{K} 0$ mouse barrel cortex. $C_{1} \mathbf{D}$, Immunohistochemistry for IP $\mathrm{R} 2$ morphology was delineated in yellow based on $\mathrm{S} 100 \mathrm{~B}$ immunohistochemistry. Filled triangles point to nonastrocytic (presumably neuronal) cells. Immunoreactivity against $I P_{3} R 2$ is predominantly localized in astrocytes.

glutamate receptors (mGluRs) via indirect activation of glutamatergic neurons, we monitored the astrocytic $\left[\mathrm{Ca}^{2+}\right]_{\mathrm{i}}$ in response to NBM stimulation in the presence of MPEP, an mGluR5 antagonist previously shown to inhibit sensory-driven astrocytic $\left[\mathrm{Ca}^{2+}\right]_{\mathrm{i}}$ (Wang and Buzsaki, 1996). Astrocytic $\left[\mathrm{Ca}^{2+}\right]_{\mathrm{i}}$ increases were observed in the presence of MPEP (stNBM $70 \pm 20 \%$ vs stNBM + MPEP $64 \pm 5 \%$ active astrocytes, $p=0.65,282$ astrocytes in 7 mice), suggesting a direct action of cholinergic afferents on astrocytes.

\section{Costimulation does not induce cortical plasticity in $\mathrm{IP}_{3} \mathrm{R} 2-\mathrm{KO}$ mice}

Next, to address the causal relationship of astrocytic $\left[\mathrm{Ca}^{2+}\right]_{\mathrm{i}}$ activity and synaptic plasticity, we investigated these evoked LFP response changes after costimulation in mice deficient of inositol 1,4,5-trisphosphate receptor type 2 (Futatsugi et al., 2005), the $\mathrm{IP}_{3} \mathrm{R}$ subtype predominantly expressed in astrocytes (Sharp et al., 
A

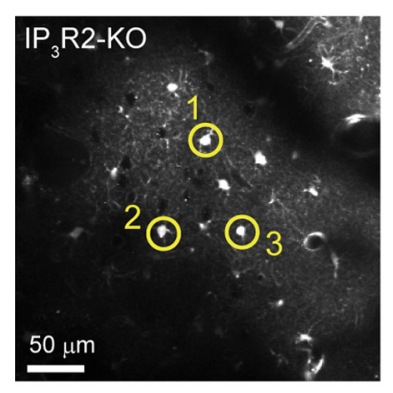

C

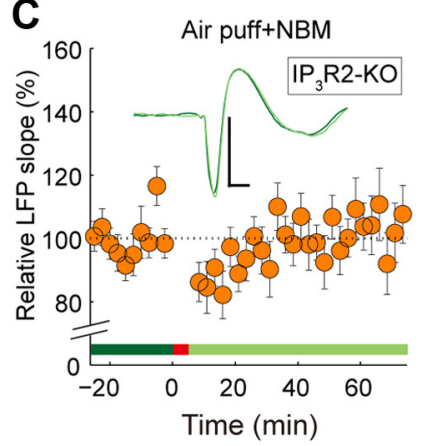

B

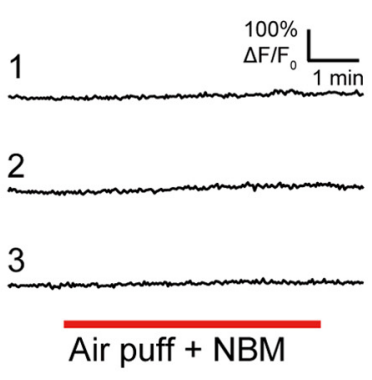

D

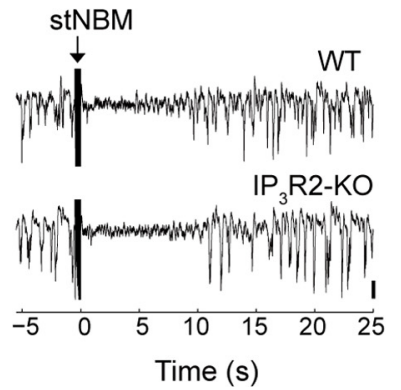

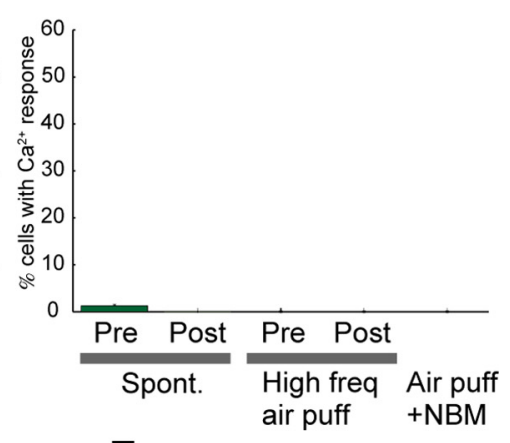

E

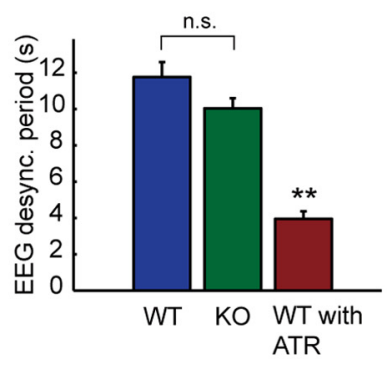

Figure 6. IP $\quad \mathrm{P}_{3} \mathrm{R2}-\mathrm{KO}$ mice do not show astrocytic $\left[\mathrm{Ca}^{2+}\right]_{\mathrm{i}}$ response or LTP upon costimulation of whisker and NBM, even though similar degrees of LFP desynchronization are triggered. $A$, Representative in vivo image of the barrel cortex in layer $2 / 3$ of $\mathrm{IP}_{3} \mathrm{R} 2-\mathrm{KO}$ mice (left) loaded with Fluo-4 AM. The costimulation of whiskers and NBM (red bar) did not induce $\left[\mathrm{Ca}^{2+}\right]_{i}$ surges in astrocytes. $\boldsymbol{B}$, Astrocytic $\left[\mathrm{Ca}^{2+}\right]_{\mathrm{i}}$ responses were virtually absent in $\mathrm{IP}_{3} \mathrm{R} 2-\mathrm{KO}$ mice. Spont., Spontaneous. C, Costimulation fails to enhance air puff triggered LFP responses in $I \mathrm{P}_{3} \mathrm{R} 2-\mathrm{KO}$ mice. Scale bar: $200 \mu \mathrm{V}, 20 \mathrm{~ms}$. D, Representative traces of LFP fluctuations in barrel cortex of WT (top trace) and IP ${ }_{3} \mathrm{R} 2-K 0$ (bottom trace) mice. Upon NBM stimulation, LFP waveforms transiently transformed from the large amplitude slow-wave state to the small amplitude desynchronized state in both WT and IP $R 2$-KO mice. E, Duration of EEG desynchronization upon NBM stimulation was similar between WT and IP $\mathrm{R} 2-\mathrm{KO}$ mice. The desynchronization was inhibited by atropine (WT or KO vs ATR, ${ }^{* *} p<0.01$ ).

1999). Using the $\mathrm{IP}_{3} \mathrm{R} 2-\mathrm{KO}$ mice as control, we confirmed the predominant localization of $\mathrm{IP}_{3} \mathrm{R} 2$ in astrocytes by double immunohistochemistry for S100B (astrocyte marker) and $\mathrm{IP}_{3} \mathrm{R} 2$, with nucleic DAPI counterstaining on barrel cortical slices (Fig. 5). As expected, there were hardly any spontaneous $\left[\mathrm{Ca}^{2+}\right]_{\mathrm{i}}$ fluctuations in $\mathrm{IP}_{3} \mathrm{R} 2-\mathrm{KO}$ mice. Moreover, neither high-frequency air puff nor costimulation resulted in significant increases of somatic $\left[\mathrm{Ca}^{2+}\right]_{\mathrm{i}}$ in astrocytes in any of our experiments (399 astrocytes in 4 mice, Fig. 6A, $B$ ). Most importantly, LFP slope enhancement was not induced after costimulation in these $\mathrm{IP}_{3} \mathrm{R} 2-\mathrm{KO}$ mice (control period vs $60 \mathrm{~min}$ after conjunctive stimulation, $100 \pm$ $5 \%, n=13$ mice, $p=0.95$; Fig. $6 C$ ).

The brain exhibits distinct network dynamics in different states of anesthesia, wakefulness, and sleep. Cerebral cortical LFP in both WT and $\mathrm{IP}_{3} \mathrm{R} 2-\mathrm{KO}$ mice in the urethane-anesthetized condition exhibited slow oscillations with alternations of the UP and DOWN states (Fig. 6D; EEG traces before stNBM). NBM stimulation (stNBM, $200 \mu \mathrm{A} 100 \mathrm{~Hz}$ for $0.5 \mathrm{~s}$ ) transformed this into the small-amplitude desynchronized pattern, a waveform resembling awake and vigilant EEG pattern (Fig. $6 D$, transient traces after stNBM), for $10.0 \pm 0.6 \mathrm{~s}$ in $\mathrm{IP}_{3} \mathrm{R} 2-\mathrm{KO}$ mice $(n=12$ mice), similar to that in WT mice (11.8 $\pm 0.5 \mathrm{~s}, n=14$ mice, $p=$ 0.11 , Fig. $6 D, E)$, indicating that the neuronal response to NBM stimulation in $\mathrm{IP}_{3} \mathrm{R} 2-\mathrm{KO}$ mice is indistinguishable. Additionally, the percentage of neurons with stNBM-induced $\left[\mathrm{Ca}^{2+}\right]_{i}$ surge in $\mathrm{IP}_{3} \mathrm{R} 2-\mathrm{KO}(13 \pm 5 \%, 1483$ neurons in 4 mice $)$ was similar to that in WT mice (Fig. 3B, $11 \pm 2 \%, 4094$ neurons in 12 mice, $p=$ 0.78 ), suggesting that the neuronal response in $\mathrm{IP}_{3} \mathrm{R} 2-\mathrm{KO}$ mice is undisturbed.

\section{NBM stimulation elevates extracellular D-Ser levels}

To examine the mechanistic consequences of astrocytic $\left[\mathrm{Ca}^{2+}\right]_{\mathrm{i}}$ surges, we measured the extracellular concentration of D-Ser, a putative gliotransmitter that functions as an obligatory coagonist of NMDARs (Schell et al., 1995) in the barrel cortex upon NBM stimulation (Fig. 7A, $1 \mathrm{~mA}, 50 \mathrm{~Hz}, 10 \mathrm{~min}$ ). NBM stimulation in WT mice resulted in an increase in the extracellular D-Ser concentration significantly higher than that in $\mathrm{IP}_{3} \mathrm{R} 2-\mathrm{KO}$ mice (WT $105 \pm 2 \%$ vs $\mathrm{KO} 96 \pm 2 \%$ at $10 \mathrm{~min}, n=12$ and 10 mice, respectively, $p<0.01$, Fig. $7 A$ ). The baseline concentration of D-Ser was similar between WT and $\mathrm{KO}$ mice (WT $4.3 \pm 0.2 \mu \mathrm{M}$ vs $\mathrm{KO} 4.1 \pm 0.4 \mu \mathrm{M}, n=16$ and 7 mice, respectively, $p=0.63$ ) and comparable to that in previous reports (Hashimoto et al., 1995; Fujihira et al., 2007). Moreover, exogenous supplementation of D-Ser (surface application at $100 \mu \mathrm{M}$ and simultaneous i.p. application at $560 \mathrm{mg} / \mathrm{kg}$ ) rescued the deficient LTP induction by costimulation in $\mathrm{IP}_{3} \mathrm{R} 2-\mathrm{KO}$ mice $(122 \pm 5 \%, n=13$ mice, $p<0.01$, Fig. $7 B, C)$. Furthermore, D- Ser supplementation to WT mice rescued LTP induction with air puffs alone $(118 \pm 5 \%, p=0.01$, $n=7$ mice). These results suggest a lack of NBM stimulation induced enhancement of extracellular D-Ser concentration in $\mathrm{IP}_{3} \mathrm{R} 2-\mathrm{KO}$ mice, leading to deficient plasticity induction.

\section{Discussion}

Although several in vivo studies have reported increased astrocytic $\left[\mathrm{Ca}^{2+}\right]_{\mathrm{i}}$ activity during pharmacological enhancement of neural activity (Hirase et al., 2004; Ding et al., 2007), during sensory stimulation (Wang et al., 2006; Petzold et al., 2008; Schummers et al., 2008) or by activation of the locus coeruleus (Bekar et al., 2008), the significance of astrocytic $\left[\mathrm{Ca}^{2+}\right]_{\mathrm{i}}$ dynam- 
ics in synaptic plasticity remains to be elucidated in vivo. Moreover, NBM stimulation was demonstrated to alter the membrane potential of cortical astrocytes (Seigneur et al., 2006), but the downstream signals and effects were unclear. Our results demonstrate that NBM activation elevates astrocytic $\left[\mathrm{Ca}^{2+}\right]_{i}$ via mAChRs, which provide a favorable condition for the induction of NMDARdependent sensory plasticity via the increased extracellular concentration of D-Ser (Fig. 7D).

The cellular origin of D-Ser increase remains to be clarified. Dominant neuronal localization of serine racemase, a key enzyme synthesizing $80-90 \%$ of D-Ser in the mouse forebrain (Horio et al., 2011), has been reported by both in situ hybridization and immunohistochemistry (Miya et al., 2008). On the other hand, immunohistochemical studies using D-Ser antisera show the dominance of D-Ser in astrocytes (Schell et al., 1995; Wako et al., 1995; Williams et al., 2006). A recent study using immunogold electron microscopy detected D-Ser in synaptic-like microvesicles near the endoplasmic reticulum (ER), a major source of $\mathrm{Ca}^{2+}$ for astrocytic $\left[\mathrm{Ca}^{2+}\right]_{\mathrm{i}}$ surges, in the perisynaptic processes of astrocytes (Bergersen et al., 2011), hinting at an ER activity-triggered release of $\mathrm{D}$-Ser. In the present study, the extracellular concentration of D-Ser was significantly higher in the first $10 \mathrm{~min}$ in WT mice than $\mathrm{IP}_{3} \mathrm{R} 2-\mathrm{KO}$ mice, while the basal level of extracellular D-Ser concentration was similar between these mice. It is intriguing to speculate that the basal extracellular D-Ser level is constitutively maintained by neurons and that astrocytes, which store D-Ser from the extracellular source, release D-Ser onto synapses in a neural activity-dependent manner (Mothet et al., 2005). Other possible mechanisms for astrocytic D-Ser release include $\mathrm{Na}^{+}$dependent alanine-serine-cysteine transporter (ASCT) and volume-regulated anion channels (O'Brien and Bowser, 2006; Rosenberg et al., 2010). Regardless of the source of D-Ser release, our data are in support of astrocytic involvement in AChmodulated, NMDAR-dependent synaptic plasticity.

In the microdialysis experiment, the intensity of NBM stimulation was higher than that in the LTP-induction experiments, resulting in 5\% increase of extracellular D-Ser. Whether such stimulation is of physiological relevance is controvertible. We shall note that the fluctuations of D-Ser concentration at the synaptic cleft could be larger than measured values by microdialysis because of the following. (1) Basal D-Ser concentrations at synaptic clefts are likely to be lower than the extrasynaptic space because the glycine-binding sites of synaptic NMDARs are reported to be unsaturated under the circumstances that the basal extracellular concentration of D-Ser (of $\mu \mathrm{M}$ order) is higher than the $K_{\mathrm{d}}$ value $(355 \mathrm{nM})$ for glycine binding to NMDAR (Danysz et al., 1990; Danysz and Parsons, 1998). Indeed, D- Ser application was effective in our in vivo experiments (Fig. $7 B$ and a result on D-Ser supplementation to WT mice). (2) Microdialysis probes detect 200 times diluted
B Air puff+NBM+D-Ser



D

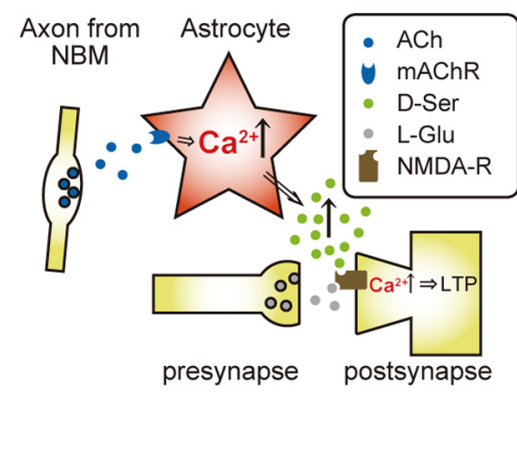

Figure 7. Extracellular D-Ser increase in response to NBM stimulation is absent in $\mathbb{P}_{3} \mathrm{R} 2-\mathrm{KO} 0$ mice. $A$, Extracellular D-Ser concentration peaks in the first 10 min after NBM stimulation (red bar) in WT mice (blue circle), in contrast to IP R2-K0 mice

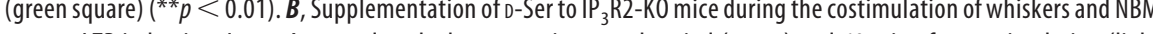
in $\mathbb{P}_{3} \mathrm{R} 2-\mathrm{K} 0$ mice at 60 min with air puff only, costimulation, or costimulation plus D-Ser supplementation, respectively $\left({ }^{* *} p<0.01\right)$. D, Proposed involvement of astrocytes in NBM-gated potentiation of synaptic transmission in the cortex.

fluctuation of D-Ser in synaptic cleft, estimated from the volume ratio of synaptic cleft and extracellular space, based on the estimation for the extracellular space accounting for $\sim 20 \%$ of the total brain volume (Syková and Nicholson, 2008), a synaptic cleft volume of $\sim 10^{-3} \mu \mathrm{m}^{3}$ (Rusakov and Kullmann, 1998), and a synaptic density of $\sim 1 \mu \mathrm{m}^{-3}$ (Schüz and Palm, 1989). (3) A proportion of released D-Ser might be removed from the extracellular space before $\mathrm{D}$-Ser reaches microdialysis probe by transporters such as neuronal alanine-serinecysteine transporter 1 (Asc-1) and glial alanine-serine-cysteine transporter 2 (ASCT2) (Rutter et al., 2007). In fact, decreases of extracellular D-Ser are reported upon prolonged depolarizing stimuli of the brain in vivo (Hashimoto et al., 1995; Rosenberg et al., 2010). Such transporters could be responsible for the decrease of extracellular $\mathrm{D}-\mathrm{Ser}$ in $\mathrm{IP}_{3} \mathrm{R} 2-\mathrm{KO}$ mice upon NBM stimulation (Fig. 7A).

Our discussion thus far focused on D-Ser because NBM stimulation increased D-Ser (Fig. 7A) and exogenous application of $D$-Ser rescued the plasticity in the absence of astrocytic $\left[\mathrm{Ca}^{2+}\right]_{i}$ signaling in $\mathrm{IP}_{3} \mathrm{R} 2-\mathrm{KO}$ mice (Fig. $7 B$ ). Our present data, however, do not exclude the involvement of other gliotransmitters such as glycine or a cascade downstream of D-Ser as endogenous molecule(s) critical for the plasticity.

There is controversy over whether astrocytic $\left[\mathrm{Ca}^{2+}\right]_{\mathrm{i}}$ elevations play a role in synaptic plasticity (Smith, 2010). A parsimonious explanation to resolve this controversy could be that astrocytic effect only becomes relevant at near-threshold condi- 
tions, as suggested by a recent elegant study investigating seizure initiation (Gómez-Gonzalo et al., 2010). Whisker stimulation provides input strength of physiological range to the cerebral cortex that may be on the threshold of plasticity induction, and therefore astrocytic mechanisms may have been critical for plasticity induction in our paradigm.

Somatic $\left[\mathrm{Ca}^{2+}\right]_{\mathrm{i}}$ activity of astrocytes was analyzed in the present study. The costimulation induced transient, large $\left[\mathrm{Ca}^{2+}\right]_{\mathrm{i}}$ increases in astrocytes in an early phase $(\sim 1 \mathrm{~min})$ of the stimulation, typically followed by a plateau of lower increase of $\left[\mathrm{Ca}^{2+}\right]_{i}$ for the rest of the stimulation. It is not clear which aspects of astrocytic $\left[\mathrm{Ca}^{2+}\right]_{\mathrm{i}}$ surges are critical for LTP induction in the current study. The magnitude of $\left[\mathrm{Ca}^{2+}\right]_{i}$ surge upon costimulation was higher than that of highfrequency air puffs alone (Fig. 2C). In addition to the magnitude, $\left[\mathrm{Ca}^{2+}\right]_{\mathrm{i}}$ surges upon whisker and NBM stimulation are distinguishable in the following aspects: (1) Whisker stimulation induced- $\left[\mathrm{Ca}^{2+}\right]_{\mathrm{i}}$ increases were blocked by an antagonist for mGluR (Wang et al., 2006), while NBM stimulationinduced $\left[\mathrm{Ca}^{2+}\right]_{\mathrm{i}}$ surges were dependent on $\mathrm{mAChR}$, but not on mGluR (Fig. $3 B$ and Results section). (2) While whiskerinduced $\left[\mathrm{Ca}^{2+}\right]_{\mathrm{i}}$ surges return to its baseline even during the stimulation (Wang et al., 2006), plateau $\left[\mathrm{Ca}^{2+}\right]_{\mathrm{i}}$ increases persisted during the period of costimulation following the initial, transient surge (Fig. $2 \mathrm{~A}$ ). The plateau $\left[\mathrm{Ca}^{2+}\right]_{\mathrm{i}}$ surge could be critical for LTP induction, because increased presentation of costimulation (up to 100 times) had been reported to drive more effective LTP (Rasmusson and Dykes, 1988). The above discussion may hint at distinct downstream cascades between $\left[\mathrm{Ca}^{2+}\right]_{\mathrm{i}}$ surges upon whisker or NBM stimulation, suggesting that the magnitude of $\left[\mathrm{Ca}^{2+}\right]_{\mathrm{i}}$ surge could not be the only account for LTP induction. Moreover, some astrocytic process level $\left[\mathrm{Ca}^{2+}\right]_{\mathrm{i}}$ activities are confined within astrocytic processes (Nett et al., 2002) and are dependent on $\mathrm{IP}_{3} \mathrm{R} 2$ (Di Castro et al., 2011), suggesting a possible enhancement of localized synaptic plasticity via an astrocyte. Future investigation on $\left[\mathrm{Ca}^{2+}\right]_{\mathrm{i}}$ activity at astrocytic fine processes should deepen our understandings of the role of astrocytes on synaptic plasticity.

Cholinergic afferents to the cerebral cortex have classically been described to be nonspecific and to regulate the ambient ACh level by volume transmission (Descarries et al., 1997), thereby controlling the general excitability of cortical neurons (Buzsaki et al., 1988). Slice experiments suggest that the membrane responses to ACh are heterogeneous in pyramidal cells and interneurons (McCormick and Prince, 1985; Xiang et al., 1998; Gulledge et al., 2007), and mAChR activation induces gamma frequency oscillations in excited network states (Buhl et al., 1998). Despite the mAChR-dependent LFP state change in anesthetized animals, the involvement of cortical cholinergic receptors in inducing small-amplitude desynchronized LFP patterns has recently been challenged in awake animals (Constantinople and Bruno, 2011). Our experiments with $\mathrm{IP}_{3} \mathrm{R} 2-\mathrm{KO}$ mice indeed dissociate LFP state changes from costimulation-induced plasticity, thereby validating the significance of astrocytic $\left[\mathrm{Ca}^{2+}\right]_{\mathrm{i}}$ in this type of plasticity. Overall, our results are compatible with the idea that the activation of NBM provides a window of opportunity for memory formation (Bakin and Weinberger, 1996; McLin et al., 2002; Miasnikov et al., 2009). In addition to neuronal activation, we propose that ACh activation of astrocytes gates synaptic plasticity. Recently, NBM stimulation has been shown to enhance information contents contained in spike trains of neurons in the visual cortex in vivo (Goard and Dan, 2009), suggesting a neuronal role of $\mathrm{ACh}$ activation to be the enhancement of sensory input (Constantinople and Bruno, 2011).

Both cholinergic and GABAergic projections arise from the NBM to the cortex. As electrical stimulation preferentially activates axons (Histed et al., 2009), the possibility that the NBM stimulation recruited GABAergic and some other axons in the neighborhood cannot be excluded. Yet, our results showing that surface application of atropine blocks the costimulation-induced plasticity and that astrocytic $\left[\mathrm{Ca}^{2+}\right]_{\mathrm{i}}$ response was inhibited by atropine but remained in the presence of MPEP favor a role of cortical $\mathrm{mAChR}$ activation on the plasticity. Future investigation to selectively stimulate cholinergic projections by, for instance, optogenetic techniques would reveal whether release of another neuromodulator in addition to ACh upon NBM stimulation is necessary for LTP induction. Interestingly, a recent study has demonstrated that a large proportion of astrocytes in the primary somatosensory cortex elevate their $\left[\mathrm{Ca}^{2+}\right]_{\mathrm{i}}$ in response to voluntary limb movements (Dombeck et al., 2007). Future studies that directly address distinct subcortical neuromodulator activation (e.g., by optogenetics), astrocytic $\left[\mathrm{Ca}^{2+}\right]_{\mathrm{i}}$ activity, and synaptic plasticity in the context of animal behavior will deepen our understanding of attention-enhanced memory formation.

\section{References}

Agulhon C, Fiacco TA, McCarthy KD (2010) Hippocampal short- and longterm plasticity are not modulated by astrocyte $\mathrm{Ca}^{2+}$ signaling. Science 327:1250-1254.

Araque A, Martín ED, Perea G, Arellano JI, Buño W (2002) Synaptically released acetylcholine evokes $\mathrm{Ca}^{2+}$ elevations in astrocytes in hippocampal slices. J Neurosci 22:2443-2450.

Bakin JS, Weinberger NM (1996) Induction of a physiological memory in the cerebral cortex by stimulation of the nucleus basalis. Proc Natl Acad Sci U S A 93:11219-11224.

Bear MF, Singer W (1986) Modulation of visual cortical plasticity by acetylcholine and noradrenaline. Nature 320:172-176.

Bekar LK, He W, Nedergaard M (2008) Locus coeruleus alpha-adrenergicmediated activation of cortical astrocytes in vivo. Cereb Cortex 18:2789-2795.

Bergersen LH, Morland C, Ormel L, Rinholm JE, Larsson M, Wold JF, Roe AT, Stranna A, Santello M, Bouvier D, Ottersen OP, Volterra A, Gundersen V (2011) Immunogold detection of L-glutamate and D-serine in small synaptic-like microvesicles in adult hippocampal astrocytes. Cereb Cortex. Advance online publication. Retrieved September 12, 2011. doi:10.1093/cercor/bhr254.

Buhl EH, Tamás G, Fisahn A (1998) Cholinergic activation and tonic excitation induce persistent gamma oscillations in mouse somatosensory cortex in vitro. J Physiol 513:117-126.

Buzsaki G, Bickford RG, Ponomareff G, Thal LJ, Mandel R, Gage FH (1988) Nucleus basalis and thalamic control of neocortical activity in the freely moving rat. J Neurosci 8:4007-4026.

Constantinople CM, Bruno RM (2011) Effects and mechanisms of wakefulness on local cortical networks. Neuron 69:1061-1068.

Danysz W, Parsons CG (1998) Glycine and N-methyl-D-aspartate receptors: physiological significance and possible therapeutic applications. Pharmacol Rev 50:597-664.

Danysz W, Fadda E, Wroblewski JT, Costa E (1990) $\left[{ }^{3} \mathrm{H}\right] \mathrm{D}$-serine labels strychnine-insensitive glycine recognition sites of rat central nervous system. Life Sci 46:155-164.

Descarries L, Gisiger V, Steriade M (1997) Diffuse transmission by acetylcholine in the CNS. Prog Neurobiol 53:603-625.

Di Castro MA, Chuquet J, Liaudet N, Bhaukaurally K, Santello M, Bouvier D, Tiret P, Volterra A (2011) Local $\mathrm{Ca}^{2+}$ detection and modulation of synaptic release by astrocytes. Nat Neurosci 14:1276-1284.

Ding S, Fellin T, Zhu Y, Lee SY, Auberson YP, Meaney DF, Coulter DA, 
Carmignoto G, Haydon PG (2007) Enhanced astrocytic $\mathrm{Ca}^{2+}$ signals contribute to neuronal excitotoxicity after status epilepticus. J Neurosci 27:10674-10684.

Dombeck DA, Khabbaz AN, Collman F, Adelman TL, Tank DW (2007) Imaging large-scale neural activity with cellular resolution in awake, mobile mice. Neuron 56:43-57.

Everitt BJ, Robbins TW (1997) Central cholinergic systems and cognition. Annu Rev Psychol 48:649-684.

Fujihira T, Kanematsu S, Umino A, Yamamoto N, Nishikawa T (2007) Selective increase in the extracellular D-serine contents by D-cycloserine in the rat medial frontal cortex. Neurochem Int 51:233-236.

Futatsugi A, Nakamura T, Yamada MK, Ebisui E, Nakamura K, Uchida K, Kitaguchi T, Takahashi-Iwanaga H, Noda T, Aruga J, Mikoshiba K (2005) IP3 receptor types 2 and 3 mediate exocrine secretion underlying energy metabolism. Science 309:2232-2234.

Gilbert ME, Mack CM (1999) Field potential recordings in dentate gyrus of anesthetized rats: stability of baseline. Hippocampus 9:277-287.

Glazewski S, Herman C, McKenna M, Chapman PF, Fox K (1998) Longterm potentiation in vivo in layers II/III of rat barrel cortex. Neuropharmacology 37:581-592.

Goard M, Dan Y (2009) Basal forebrain activation enhances cortical coding of natural scenes. Nat Neurosci 12:1444-1449.

Gómez-Gonzalo M, Losi G, Chiavegato A, Zonta M, Cammarota M, Brondi M, Vetri F, Uva L, Pozzan T, de Curtis M, Ratto GM, Carmignoto G (2010) An excitatory loop with astrocytes contributes to drive neurons to seizure threshold. PLoS Biol 8:e1000352.

Gulledge AT, Park SB, Kawaguchi Y, Stuart GJ (2007) Heterogeneity of phasic cholinergic signaling in neocortical neurons. J Neurophysiol 97:2215-2229.

Hamase K, Miyoshi Y, Ueno K, Han H, Hirano J, Morikawa A, Mita M, Kaneko T, Lindner W, Zaitsu K (2010) Simultaneous determination of hydrophilic amino acid enantiomers in mammalian tissues and physiological fluids applying a fully automated micro-two-dimensional highperformance liquid chromatographic concept. J Chromatogr A 1217:1056-1062.

Hashimoto A, Oka T, Nishikawa T (1995) Extracellular concentration of endogenous free $\mathrm{D}$-serine in the rat brain as revealed by in vivo microdialysis. Neuroscience 66:635-643.

Henneberger C, Papouin T, Oliet SH, Rusakov DA (2010) Long-term potentiation depends on release of D-serine from astrocytes. Nature 463:232-236.

Hirase H, Qian L, Barthó P, Buzsáki G (2004) Calcium dynamics of cortical astrocytic networks in vivo. PLoS Biol 2:E96.

Histed MH, Bonin V, Reid RC (2009) Direct activation of sparse, distributed populations of cortical neurons by electrical microstimulation. Neuron 63:508-522.

Horio M, Kohno M, Fujita Y, Ishima T, Inoue R, Mori H, Hashimoto K (2011) Levels of D-serine in the brain and peripheral organs of serine racemase (Srr) knock-out mice. Neurochem Int 59:853-859.

Kilgard MP, Merzenich MM (1998) Cortical map reorganization enabled by nucleus basalis activity. Science 279:1714-1718.

Kurosawa M, Sato A, Sato Y (1989) Stimulation of the nucleus basalis of Meynert increases acetylcholine release in the cerebral cortex in rats. Neurosci Lett 98:45-50.

McCormick DA, Prince DA (1985) Two types of muscarinic response to acetylcholine in mammalian cortical neurons. Proc Natl Acad Sci U S A 82:6344-6348.

McLin DE 3rd, Miasnikov AA, Weinberger NM (2002) Induction of behavioral associative memory by stimulation of the nucleus basalis. Proc Natl Acad Sci U S A 99:4002-4007.

Metherate R, Tremblay N, Dykes RW (1987) Acetylcholine permits longterm enhancement of neuronal responsiveness in cat primary somatosensory cortex. Neuroscience 22:75-81.

Metherate R, Cox CL, Ashe JH (1992) Cellular bases of neocortical activation: modulation of neural oscillations by the nucleus basalis and endogenous acetylcholine. J Neurosci 12:4701-4711.

Miasnikov AA, Chen JC, Weinberger NM (2009) Behavioral memory induced by stimulation of the nucleus basalis: effects of contingency reversal. Neurobiol Learn Mem 91:298-309.

Miya K, Inoue R, Takata Y, Abe M, Natsume R, Sakimura K, Hongou K,
Miyawaki T, Mori H (2008) Serine racemase is predominantly localized in neurons in mouse brain. J Comp Neurol 510:641-654.

Miyoshi Y, Hamase K, Tojo Y, Mita M, Konno R, Zaitsu K (2009) Determination of D-serine and D-alanine in the tissues and physiological fluids of mice with various $\mathrm{D}$-amino-acid oxidase activities using two-dimensional high-performance liquid chromatography with fluorescence detection. J Chromatogr B Analyt Technol Biomed Life Sci 877:2506-2512.

Mothet JP, Pollegioni L, Ouanounou G, Martineau M, Fossier P, Baux G (2005) Glutamate receptor activation triggers a calcium-dependent and SNARE protein-dependent release of the gliotransmitter D-serine. Proc Natl Acad Sci U S A 102:5606-5611.

Nett WJ, Oloff SH, McCarthy KD (2002) Hippocampal astrocytes in situ exhibit calcium oscillations that occur independent of neuronal activity. J Neurophysiol 87:528-537.

O'Brien KB, Bowser MT (2006) Measuring D-serine efflux from mouse cortical brain slices using online microdialysis-capillary electrophoresis. Electrophoresis 27:1949-1956.

Oldford E, Castro-Alamancos MA (2003) Input-specific effects of acetylcholine on sensory and intracortical evoked responses in the "barrel cortex" in vivo. Neuroscience 117:769-778.

Perea G, Araque A (2007) Astrocytes potentiate transmitter release at single hippocampal synapses. Science 317:1083-1086.

Petzold GC, Albeanu DF, Sato TF, Murthy VN (2008) Coupling of neural activity to blood flow in olfactory glomeruli is mediated by astrocytic pathways. Neuron 58:897-910.

Rasmusson DD, Dykes RW (1988) Long-term enhancement of evoked potentials in cat somatosensory cortex produced by co-activation of the basal forebrain and cutaneous receptors. Exp Brain Res 70:276-286.

Rosenberg D, Kartvelishvily E, Shleper M, Klinker CM, Bowser MT, Wolosker H (2010) Neuronal release of D-serine: a physiological pathway controlling extracellular D-serine concentration. FASEB J 24:2951-2961.

Rusakov DA, Kullmann DM (1998) Extrasynaptic glutamate diffusion in the hippocampus: ultrastructural constraints, uptake, and receptor activation. J Neurosci 18:3158-3170.

Rutter AR, Fradley RL, Garrett EM, Chapman KL, Lawrence JM, Rosahl TW, Patel S (2007) Evidence from gene knockout studies implicates Asc-1 as the primary transporter mediating $\mathrm{d}$-serine reuptake in the mouse CNS. Eur J Neurosci 25:1757-1766.

Sakatani S, Seto-Ohshima A, Itohara S, Hirase H (2007) Impact of S100B on local field potential patterns in anesthetized and kainic acid-induced seizure conditions in vivo. Eur J Neurosci 25:1144-1154.

Sarter M, Hasselmo ME, Bruno JP, Givens B (2005) Unraveling the attentional functions of cortical cholinergic inputs: interactions between signal-driven and cognitive modulation of signal detection. Brain Res Brain Res Rev 48:98-111

Sasaki T, Matsuki N, Ikegaya Y (2011) Action-potential modulation during axonal conduction. Science 331:599-601.

Schell MJ, Molliver ME, Snyder SH (1995) D-serine, an endogenous synaptic modulator: localization to astrocytes and glutamate-stimulated release. Proc Natl Acad Sci U S A 92:3948-3952.

Schummers J, Yu H, Sur M (2008) Tuned responses of astrocytes and their influence on hemodynamic signals in the visual cortex. Science 320:1638-1643

Schüz A, Palm G (1989) Density of neurons and synapses in the cerebral cortex of the mouse. J Comp Neurol 286:442-455.

Seigneur J, Kroeger D, Nita DA, Amzica F (2006) Cholinergic action on cortical glial cells in vivo. Cereb Cortex 16:655-668.

Sharp AH, Nucifora FC Jr, Blondel O, Sheppard CA, Zhang C, Snyder SH, Russell JT, Ryugo DK, Ross CA (1999) Differential cellular expression of isoforms of inositol 1,4,5-triphosphate receptors in neurons and glia in brain. J Comp Neurol 406:207-220.

Shelton MK, McCarthy KD (2000) Hippocampal astrocytes exhibit $\mathrm{Ca}^{2+}$. elevating muscarinic cholinergic and histaminergic receptors in situ. J Neurochem 74:555-563.

Smith K (2010) Neuroscience: Settling the great glia debate. Nature 468:160-162.

Stellwagen D, Malenka RC (2006) Synaptic scaling mediated by glial TNFalpha. Nature 440:1054-1059.

Steriade M (1997) Synchronized activities of coupled oscillators in the cerebral cortex and thalamus at different levels of vigilance. Cereb Cortex 7:583-604. 
Syková E, Nicholson C (2008) Diffusion in brain extracellular space. Physiol Rev 88:1277-1340.

Takata N, Hirase H (2008) Cortical layer 1 and layer $2 / 3$ astrocytes exhibit distinct calcium dynamics in vivo. PLoS ONE 3:e2525.

Van Der Zee EA, De Jong GI, Strosberg AD, Luiten PG (1993) Muscarinic acetylcholine receptor-expression in astrocytes in the cortex of young and aged rats. Glia 8:42-50.

Wako K, Ma N, Shiroyama T, Semba R (1995) Glial uptake of intracerebroventricularly injected D-serine in the rat brain: an immunocytochemical study. Neurosci Lett 185:171-174.

Wang X-J, Buzsáki G (1996) Gamma oscillation by synaptic inhibition in a hippocampal interneuronal network model. J Neurosci 16:64026413.
Wang X, Lou N, Xu Q, Tian GF, Peng WG, Han X, Kang J, Takano T, Nedergaard M (2006) Astrocytic $\mathrm{Ca}^{2+}$ signaling evoked by sensory stimulation in vivo. Nat Neurosci 9:816-823.

Williams SM, Diaz CM, Macnab LT, Sullivan RK, Pow DV (2006) Immunocytochemical analysis of D-serine distribution in the mammalian brain reveals novel anatomical compartmentalizations in glia and neurons. Glia 53:401-411.

Xiang Z, Huguenard JR, Prince DA (1998) Cholinergic switching within neocortical inhibitory networks. Science 281:985-988.

Yang Y, Ge W, Chen Y, Zhang Z, Shen W, Wu C, Poo M, Duan S (2003) Contribution of astrocytes to hippocampal long-term potentiation through release of D-serine. Proc Natl Acad Sci U S A 100:1519415199. 